\title{
DEZ ANOS DA REDE FEDERAL DE EDUCAÇÃO PROFISSIONAL, CIENTÍFICA E TECNOLÓGICA: UM BALANÇO DA EFETIVAÇÃO HISTÓRICA DO SEU PROJETO POLÍTICO EDUCACIONAL
}

\author{
Lucas Alves Marinho, Pablo Menezes e Oliveira \\ Instituto Federal de Minas Gerais - Campus Governador Valadares \\ DOI: $10.15628 /$ rbept.2019.9102
}

Artigo submetido em out/2019 e aceito em nov/2019

\begin{abstract}
RESUMO
Há pouco mais de dez anos, a Rede Federal de Educação Profissional, Científica e Tecnológica (RFEPCT) era instituída pela Lei 11.892, de 29 de Dezembro de 2008. Neste momento oportuno, que marca a primeira década de existência da RFEPCT, este artigo avalia a composição da oferta de vagas da RFEPCT, a partir do estudo do caso do Instituto Federal de Minas Gerais (IFMG). Demonstrando: que essa oferta persiste inadequada, apesar da clareza com que a Lei 11.892 orientou a sua composição; que os desvios observados têm conduzido ao abandono persistente da oferta de vagas em modalidades legalmente prioritárias; por fim, que as razões explícitas com as quais se tem pretendido justificar essa inadequação não se sustentam.
\end{abstract}

Palavras-Chave: educação profissional e tecnológica. Lei 11.892/2008. políticas públicas. Rede Federal de Educação Profissional, Científica e Tecnológica.

\section{THE REDE FEDERAL DE EDUCAÇÃO PROFISSIONAL, CIENTÍFICA E TECNOLÓGICA: A BALANCE OF THE FIRST DECADE OF HISTORICAL REALIZATION OF ITS POLITICAL EDUCATIONAL PROJECT}

\begin{abstract}
A little more than ten years ago, the Rede Federal de Educação Profissional Científica e Tecnológica (RFEPCT) was established by the law 11.892/2008. The completion of a decade since its implementation provides a great opportunity to analyse the composition of its educational offer. This article presents a case study of Instituto Federal de Minas Gerais (IFMG). We indicate that the referred educational offer is inadequate despite the unambiguity of the law which guided its composition; the deviations showed a persistent neglect of priority modalities access and a correspondent excess admission on what should be the residual offer of the RFEPCT. Finally, we argue that the explanations given to justify such implementation are not plausible.
\end{abstract}

Keywords: history of professional and technological education. Law 11.892/2008. public policies. Rede Federal de Educação Profissional, Científica e Tecnológica. 


\section{DO DESAFIO HISTÓRICO PROPOSTO PELA LEI 11.892/2008}

Síntese de um longo debate nacional, a publicação da Lei 11.892, em 29 de Dezembro de 2008 - instituindo a Rede Federal de Educação Profissional, Científica e Tecnológica e criando os Institutos Federais de Educação, Ciência e Tecnologia - impulsionou decisivamente o movimento histórico mais recente de expansão das escolas técnicas federais. Conferindo-Ihe a devida organicidade pelo estabelecimento das seguintes diretrizes legais básicas, concernentes ao seu novo conjunto de objetivos e finalidades: i) oferta de educação profissional e tecnológica (entendida esta oferta como processo investigativo e criativo a ser vinculado, de forma indissociável, a atividades de pesquisa e extensão) para geração e adaptação de soluções a demandas sociais, visando o fortalecimento de arranjos produtivos locais e regionais (Lei 11.892/2008, art. 6o, I); ii) integração e verticalização da estrutura curricular e da estrutura dos cursos ofertados em cada campus, da educação básica à educação profissional e superior (Lei $11.892 / 2008$, art. $6^{\circ}$, III); iii) constituição de centros de referência no apoio à oferta do ensino de ciências, capacitação técnica e atualização pedagógica dos docentes das redes públicas de ensino (Lei 11.892/2008, art. 6o, V); e à nova composição da sua oferta de vagas: i) mínimo de $50 \%$ das vagas para ministrar educação profissional técnica de nível médio, prioritariamente na forma de cursos integrados, para os concluintes do ensino fundamental e para o público da educação de jovens e adultos (Lei 11.892/2008, Art. 8o); ii) mínimo de $20 \%$ das vagas para cursos de licenciatura, bem como programas especiais de formação pedagógica para a educação básica, sobretudo nas áreas de ciências e matemática, e para a educação profissional (Lei $11.892 / 2008$, art. $8^{\circ}$ ); ficando, então, disponíveis os iii) 30\% restantes para a oferta de vagas em cursos de bacharelado e engenharia, pós-graduação lato sensu e pós-graduação stricto sensu; iv) por fim, mínimo de dez por cento do total das vagas para a oferta de educação profissional para jovens e adultos (Decreto 5840/2016, que instituiu o PROEJA).

Ao que se fez questão de acrescentar, em publicação oficial que reuniu os comentários dos então responsáveis pela gestão da Secretaria de Educação Tecnológica do Ministério da Educação à Lei 11.892, que o atendimento a essa composição legal da oferta de vagas era algo indispensável para efetivar os objetivos e finalidades do projeto políticoeducacional representado pela criação da RFEPCT. Buscava-se, neste ponto, inclusive, limitar a autonomia institucional para definição do perfil de ofertas de vagas, de modo a obrigar o cumprimento do exposto em lei, conforme se vê no seguinte trecho da referida publicação:

Como o limite da autonomia das autarquias é definido pelos fins para os quais elas são criadas, a lei estabelece referenciais de atendimento em diferentes ofertas educativas, explicitando a atuação mínima requerida nas diferentes faces do serviço público

1 Antes dessa reestruturação mais recente, iniciada em 2008, a história da Rede Federal de Educação Profissional, Científica e Tecnológica compreendeu outras duas fases fundamentais: a primeira, quando da criação, em 1909, por Nilo Peçanha, de 19 escolas de Aprendizes e Artífices; a segunda, marcada pela instituição do Sistema Nacional de Educação Tecnológica e criação dos CEFET's, a partir de 1994. 
prestado pela instituição. Tal ação tem como objetivo resguardar a proporcionalidade da oferta entre os diferentes cursos a fim de garantir a consecução de um projeto político educacional. (SILVA, 2009. p. 45-46.)

Impondo-se, portanto, à RFEPCT, por determinação legal, a necessidade de uma "profunda revisão e atualização na sua forma tradicional de atuação, organização e gestão" (CARDOSO, 2016, p. 37). Cujos desafios concentraram-se em torno de dois pontos-chave, priorizados claramente quando da especificação legal das formas de oferta da RFEPCT: a centralidade da educação profissional, devendo fundar, em torno dos seus eixos tecnológicos, a construção da integração e verticalização curriculares entre os diversos níveis e modalidades de ensino, desde o ensino médio até a pós-graduação, em cada campus; e a atenção à formação de profissionais já atuantes (jovens, adultos e professores), buscando motivar, por sua vez, um engajamento permanente em demandas oriundas da dinâmica do trabalho, em suas respectivas regiões de atuação. Projeto suficientemente arrojado para pretender modificações consideráveis nos modelos nacionais de ensino médio e ensino superior. Superando a sua tradicional cisão, por uma nova relação de radical articulação, na qual ambos os níveis de ensino (respeitando a indissociabilidade entre ensino, pesquisa e extensão), ora constituídos seus projetos através de eixos tecnológicos comuns e conduzidos por corpos docentes únicos, conviveriam também nos mesmos espaços de ensino-aprendizagem - aliás, num sentido que inverteria o habitual privilégio hierárquico do ensino superior, uma vez que os eixos tecnológicos fundantes de cada unidade da rede derivariam diretamente dos cursos técnicos integrados ali ofertados ${ }^{2}$.

Com os institutos federais, o governo brasileiro, através do Ministério da Educação, ousa criar uma institucionalidade absolutamente nova e inovadora capaz de revolucionar a educação profissional e tecnológica de nosso país. Entretanto, - futuro dos institutos está em aberto, dependendo de nossa ousadia, competência e compromisso político com um país soberano, democrático e justo socialmente... A denominação instituições de educação superior, básica e profissional confere aos institutos federais uma natureza singular, na medida não ser comum no sistema educacional brasileiro atribuir a uma única instituição a atuação em mais de um nível de ensino...Essa diversidade não pode ser confundida com dispersão. Não se trata de um conjunto aleatório de cursos... A estruturação da oferta educativa passa pelo processo de identificação dos ingredientes tecnológicos básicos do curso -bases tecnológicas -; dos arranjos lógicos constituído por essas bases matrizes tecnológicas -; e da linha central que perpassa transversalmente essas matrizes sustentando a organização curricular e a identidade dos cursos, imprimindo a direção dos seus projetos pedagógicos - eixo tecnológico. (SILVA, 2009. p. 23)

2 A classificação e constituição básica desses eixos tecnológicos foi determinada pela Portaria MEC ํㅛ 870, de 16 de Julho de 2008. 
Pois bem, passados 10 anos da instituição desse arrojado projeto, perguntemos por sua realização, até aqui - atentando, especialmente, às seguintes questões: como se apresenta, atualmente, a composição da oferta de vagas na RFEPCT? Aqueles critérios definidos por lei para promover as finalidades da RFEPCT foram observados? Se não, haverá razões plausíveis para a não efetivação do perfil de oferta legalmente determinado quando da criação da REFEPCT?

Para responder a estas perguntas, reconhecendo a impossibilidade de avaliar-se detalhadamente, neste espaço, a composição da oferta de toda a RFEPCT, em razão da extensão e diversidade alcançadas por si no período, nos concentraremos no estudo do caso do Instituto Federal de Minas Gerais (IFMG). A análise do caso do IFMG apresentará números referentes aos status acadêmicos dos alunos da instituição, matriculados entre 2004 e 2017; às ofertas de vagas realizadas nos processos seletivos do segundo semestre de 2017 e no primeiro semestre de 2018; e avaliará: a sua composição (perguntando por sua tipicidade); alguns quesitos da sua eficiência mais afeitos aos propósitos do trabalho, agrupados por modalidade de ensino; e uma projeção da capacidade institucional ainda existente para expansão da oferta de vagas e correção de suas possíveis distorções. Cumpre destacar que, conforme o disposto no Art. $8^{\circ}, \S^{\circ}{ }^{\circ}$ da Lei 11.892, consideraremos 0 conceito de aluno-equivalente, ou seja, as matrículas e as vagas ofertadas, excetuando-se os casos devidamente assinalados, serão ponderadas de acordo com a seguinte fórmula: (carga horária mínima do curso/duração em anos do curso/800 horas) * fator de esforço do curso. ${ }^{3}$

\section{DA ATUAL OFERTA DE VAGAS DO INSTITUTO FEDERAL DE MINAS GERAIS ANTE A COMPOSIÇÃO DETERMINADA PELA LEI 11.892/2008}

Em números absolutos, não ponderados, somando-se os processos seletivos de 2017.2 e 2018.1, o IFMG ofertou as seguintes quantidades de vagas, cursos e relações vagas/curso, por modalidade de ensino:

Tabela 1 - número de vagas ofertadas, cursos e relação vagas ofertadas/curso, por nível/modalidade de ensino: 2017.2 e 2018.1

\begin{tabular}{|l|l|l|l|}
\hline $\begin{array}{l}\text { Nível/Modalidade de } \\
\text { ensino }\end{array}$ & $\begin{array}{l}\text { Número de vagas } \\
\text { ofertadas }\end{array}$ & Número de Cursos & $\begin{array}{l}\text { Relação } \\
\text { ofertadas /curso }\end{array}$ \\
\hline Técnico integrado & 1951 & 40 & 48,8 \\
\hline Técnico subsequente & 843 & 22 & 38,3 \\
\hline Técnico PROEJA & 0 & 0 & 0 \\
\hline Licenciatura & 325 & 8 & 40,6 \\
\hline Superior de tecnologia & 326 & 9 & 36,2 \\
\hline Bacharelado & 1278 & 31 & 41,2 \\
\hline Pós graduação & 256 & 7 & 36,6 \\
\hline Total IFMG & 4979 & 117 & 42,6 \\
\hline Fon: & & $7 ;$ &
\end{tabular}

Fonte: Edital IFMG oㅡ 62, 30 de Maio de 2017; Edital IFMG oㅜ 92, de 20 de Setembro de 2017.

3 Conforme disposto na Portaria MEC/SETEC №25, de 13 de Agosto de 2015. 
O que, em vagas ponderadas, revela a destinação geral das vagas da instituição, no período, como segue:

Tabela 2 - distribuição percentual geral da oferta de vagas do IFMG, por nível/modalidade de ensino: 2017.2 e 2018.1

\begin{tabular}{|l|l|}
\hline Nível/Modalidade de ensino & \% do total de vagas ofertadas \\
\hline Técnico integrado & 39 \\
\hline Técnico subsequente & 17 \\
\hline Técnico PROEJA & 0 \\
\hline Licenciatura & 6,5 \\
\hline Superior de tecnologia & 6,5 \\
\hline Bacharelado & 26 \\
\hline Pós-graduação & 5 \\
\hline Total IFMG & 100 \\
\hline
\end{tabular}

Fonte: Sistema de Gestão Acadêmica do IFMG

Os dados acima apresentados evidenciam desde já duas inadequações entre a oferta de vagas da instituição e as determinações legais já referidas: a inexistência de oferta de vagas na educação profissional para formação de jovens e adultos, apesar de $56 \%$ das vagas estarem destinadas à educação profissional; e a oferta de apenas $6,5 \%$ das vagas em cursos de licenciatura - desconsiderando-se a possível oferta de vagas para formação de professores em cursos de pós-graduação, por sua irrelevância quantitativa -, quando a legislação determina que os Institutos Federais ofertem, para cada uma dessas modalidades, respectivamente, os mínimos de $10 \%$ e $20 \%$ das vagas disponíveis. Ocorre que a constatação dessa distorção geral não é suficiente. A RFEPCT estruturou-se em torno de uma destacadíssima necessidade de efetivação regionalizada do seu bem determinado perfil de atuação; portanto, se quisermos compreender algo a respeito do equilíbrio, da razoabilidade dos propósitos subjacentes ao processo de expansão das unidades que compõem a Rede, será preciso sempre avaliar se o quadro geral da oferta de vagas dos Institutos Federais de Educação, Ciência e Tecnologia não esconderia possíveis distorções mais graves, em cada uma das suas regiões de atuação.

Analisemos, então, separadamente, a distribuição das vagas nas quatro regiões de atuação direta dos 17 campi do IFMG, no mesmo período: 2017.2 e 2018.1 - de acordo com a sua incidência regional: Região Oeste (Arcos, Bambuí, Formiga e Piumhi); Região Metropolitana de Belo Horizonte (Betim, Ribeirão das Neves, Sabará e Santa Luzia); Região dos Inconfidentes (Congonhas, Conselheiro Lafaiete, Itabirito, Ouro Branco, Ouro Preto e Ponte Nova); Região do Rio Doce (Ipatinga, Governador Valadares e São João Evangelista). 
Tabela 3 - composição (\%) da oferta de vagas, por região, 2017.

\begin{tabular}{|l|l|l|l|l|}
\hline & Região Oeste & $\begin{array}{l}\text { Região } \\
\text { Metropolitana }\end{array}$ & $\begin{array}{l}\text { Região dos } \\
\text { Inconfidentes }\end{array}$ & $\begin{array}{l}\text { Região do } \\
\text { Rio Doce }\end{array}$ \\
\hline Técnico integrado & $39 \%$ & $62 \%$ & $53 \%$ & $49 \%$ \\
\hline Técnico subsequente & $13 \%$ & $3 \%$ & $28 \%$ & $15 \%$ \\
\hline Técnico PROEJA & $0 \%$ & $0 \%$ & $0 \%$ & $0 \%$ \\
\hline Licenciatura & $12 \%$ & $0 \%$ & $7 \%$ & $4 \%$ \\
\hline Superior de tecnologia & $2 \%$ & $7 \%$ & $2 \%$ & $10 \%$ \\
\hline Bacharelado & $34 \%$ & $28 \%$ & $10 \%$ & $22 \%$ \\
\hline
\end{tabular}

Fonte: Sistema de Gestão Acadêmica do IFMG.

Têm-se, portanto, as mesmas inadequações. Reproduzidas, de forma mais ou menos grave, em todas as regiões de atuação da instituição: inexistência de oferta em cursos técnicos de nível médio PROEJA; e déficit em vagas para licenciaturas e demais cursos de formação de professores. Ao que se acrescenta uma relevante informação, não perceptível no quadro geral da oferta: em três das quatro regiões analisadas, o déficit de vagas destinadas à formação de professores está relacionado a um excesso, entre $5,5 \%$ e $11 \%$ para além do que determina a legislação, em cursos de bacharelado e cursos superiores de tecnologia.

\section{DAS RAZÕES DA RECUSA INSTITUCIONAL À EFETIVAÇÃO DO PERFIL DE ATUAÇÃO DETERMINADO LEGALMENTE}

Quais serão as razões dessa persistente recusa às determinações legais e consequente ameaça intestina à realização do projeto nacional representado pela instituição da Rede Federal de Educação Profissional, Científica e Tecnológica, no caso analisado? Estarão elas, embora em desacordo com a legislação, registradas nos documentos oficiais da instituição, fundadas em compromissos públicos como expressão consciente da vontade majoritária da comunidade acadêmica? Serão justificáveis, ou seja, terão representado uma correção consciente de rumos originais insustentáveis por sua ineficiência? Corresponderão a um caso isolado ou a um caso típico, na RFEPCT?

Começando pela questão intermediária, obviamente não existem quaisquer registros oficiais que indiquem um posicionamento institucional consciente nesse sentido divergente da legislação. Pelo contrário, no Projeto Político Pedagógico do IFMG, reproduzem-se literalmente aquelas determinações da Lei 11.982, concernentes à composição da oferta de vagas. 4

No entanto, embora não explicitada oficialmente, é bastante comum nas instâncias decisórias da instituição a recorrência à hipótese da inevitabilidade da correção dos rumos determinados por lei, em torno dos seguintes argumentos básicos: "a ineficiência dos cursos de Licenciatura e PROEJA, por suas elevadas taxas de evasão e retenção, não justificam a

4 Resolução IFMG/CONSUP ㄲo12/2014: Projeto Político Pedagógico do IFMG disponível em: $\quad$ https://www2.ifmg.edu.br/portal/acesso-ainformacao/institucional/resolucao-012-2014-ppi-09-06-14 projeto-pedagogico.pdf/view 
alocação dos nossos recursos"; e: "os cursos de Bacharelado atendem mais adequadamente aos anseios das comunidades regionais, sendo, por isto, bastante eficientes" - entendida, a eficiência ou sustentabilidade dos cursos, como potencial relativo de matrículas continuadas e sua conversão periódica em receita orçamentária. Ignoremos, por benevolência, o que mais importa: a especial relevância social das ofertas menosprezadas. E coloquemos à prova essas afirmações, geralmente acompanhadas por entonações bastante seguras, a ver se elas se sustentam quando avaliadas por seu próprio estreitíssimo viés orçamentário. Para tanto, renunciemos também, de uma vez, ao caso do PROEJA - porque ele se nos apresenta como um autêntico problema metafísico, ou seja, não verificável; e concentremo-nos em alguns indicadores que pretensamente justificariam aquelas afirmações: indicadores referentes à evasão; à média de vagas ofertadas; às matrículas ativas, por curso; e à relação esforço docente/alunos atendidos dos cursos de Bacharelado e Licenciatura.

As informações referentes aos indicadores de eficiência acadêmica foram elaboradas a partir de dados brutos extraídos do sistema integrado de gestão acadêmica da instituição e agrupam os alunos ingressantes entre 2004 e 2017, classificando-os como: evadidos; concluintes ou em curso. Comparando as taxas referentes aos cursos de Licenciatura e Bacharelado da instituição, teremos:

Tabela 4: taxas de conclusão, evasão e matrículas continuadas em curso (2004 a 2017)

\begin{tabular}{|l|l|l|l|}
\hline & Conclusão & Evasão & Em curso \\
\hline Licenciatura & $13,6 \%$ & $46,5 \%$ & $39,9 \%$ \\
\hline Bacharelado & $11,5 \%$ & $28,8 \%$ & $59,7 \%$ \\
\hline
\end{tabular}

Fonte: sítio eletrônico do IFMG: https://www2.ifmg.edu.br/portal/ensino/ensino-em-numeros.

Parecendo, a princípio, que a realidade dos cursos justificaria aquela hipótese de correção histórica de rumos pela insustentabilidade da composição da oferta de vagas determinada legalmente, quando da instituição da RFEPCT. Mas se avançarmos em nossa análise, o cenário não permitirá que assumamos esta hipótese. Apesar da maior taxa de evasão, os cursos de Licenciatura da instituição apresentam, no período, maiores taxas de conclusão de curso. Indicando, portanto, que a diferença de aproximadamente $20 \%$, entre as taxas de alunos em curso, nos cursos de Licenciatura (39.9\%) e Bacharelado (59.7\%), dever-se-á, antes, à menor longevidade relativa dos cursos de Bacharelado - uma vez que, 10 dentre os 24 cursos de Bacharelado ofertados no período analisado ainda não haviam concluído o seu primeiro ciclo de formação, contra apenas 1 dentre os oito cursos de Licenciatura.

Os demais indicadores (média de vagas ofertadas; matrículas ativas; relação esforço docente/alunos atendidos) permitirão comparar, na sequência, a relação entre o esforço institucional - especialmente no que diz respeito ao trabalho docente, em sala de aula - e os alunos atendidos, em ambos os tipos de oferta. Anotando, antes, que os custos para construção e manutenção dos espaços e equipamentos pedagógicos são certamente e consideravelmente mais elevados nos cursos de Bacharelado em Engenharias do que nos cursos de Licenciatura. 
Tabela 5: indicadores de oferta de vagas 2017.2 e 2018.1 (agregado)

\begin{tabular}{|l|l|l|l|}
\hline & Vagas ofertadas & Quantidade de cursos & Vagas ofertadas/curso \\
\hline Licenciatura & 325 & 8 & 41 \\
\hline Bacharelado & 1278 & 31 & 41 \\
\hline
\end{tabular}

Fonte: IFMG Edital ํo 62, 30 de Maio de 2017; IFMG Edital ํo 92, de 20 de Setembro de 2017.

Tabela 6: indicadores de esforço letivo por matrícula atendida.

\begin{tabular}{|l|l|l|l|}
\hline & $\begin{array}{l}\text { Carga horária total } \\
\text { dos cursos }\end{array}$ & $\begin{array}{l}\text { Total de matrículas } \\
\text { ativas }\end{array}$ & $\begin{array}{l}\text { Matrículas atendidas, } \\
\text { por hora letiva } \\
\text { docente }\end{array}$ \\
\hline Licenciatura & 25254 & 1022 & 25 \\
\hline Bacharelado & 113059 & 4511 & 25 \\
\hline
\end{tabular}

Fonte: próprio autor, a partir de dados primários extraídos do sistema de gestão acadêmica da instituição em 26/10/2018.

Uma vez apresentados esses indicadores em sua absoluta crueza, correspondente à estreiteza da noção de "eficiência" que tem balizado, como dissemos, o discurso desfavorável à ampliação da oferta dos cursos de Licenciatura e PROEJA, impõe-se a conclusão de que, no caso do IFMG, são falsos os argumentos utilizados para justificação desses desvios na sua oferta de vagas. Evidenciando-se, portanto, que a legislação da RFEPCT tem sido interditada historicamente nesses seus tópicos fundamentais por causas básicas de outra natureza: não explicitadas, portanto, não redutíveis a essa dimensão do simples respeito ou desrespeito às determinações legais pelo uso consciente da autonomia institucional.

Para alcançar tais causas não explicitadas será preciso começar por compreender que as histórias anteriores das instituições, a partir das quais se foi reestruturando a rede federal no país, exerceram considerável influência na realização desse novo projeto, especialmente na gradativa recomposição da sua oferta de vagas, apesar do evidente esforço legal para evitar que aquelas diversas tradições se impusessem, ao tornar força de lei os perfis de oferta pretendidos. O Instituto Federal de Minas Gerais (IFMG), sob nossa análise, foi criado a partir da união do CEFET Ouro Preto, que contava com uma Unidade descentralizada (UNED) em Congonhas; do CEFET Bambuí, que contava com uma UNED na Cidade de Formiga; e da Escola Agrotécnica Federal de São João Evangelista. O campus Ouro Preto era herdeiro de uma instituição criada no ano de 1944; o Campus Bambuí iniciara seus trabalhos em 1958; já a origem do campus São João Evangelista remonta a 1972. O primeiro, em região cuja economia está baseada na mineração e siderurgia; os dois últimos, em regiões de tradição agrária. A formação do IFMG ocorre, portanto, a partir de três instituições até então independentes, presentes em três diferentes regiões do estado, com histórias longevas e diferentes culturas institucionais, já sedimentadas em suas respectivas comunidades acadêmicas. Certamente, essas culturas institucionais historicamente sedimentadas vieram a ser basilares para o entendimento, a apropriação e a condução dos novos rumos projetados em 2008, sob o impacto da promulgação da Lei 11.892 .

Analisando-se o caso do IFMG, destacam-se três fatores que, derivando sua força combinada dessa história institucional precedente, 
acabaram sobrepondo-se, no geral, à pretendida determinação consciente do projeto ${ }^{5}$ : i) segmentos dos perfis de oferta já suficientemente sedimentados na história de cada campus foram sistematicamente transplantados para os campi criados após o ano de 2008, por estarem mais ou menos diretamente ligados à formação dos docentes vindos dos campi originários nomeados como seus primeiros diretores gerais; tendência que acabou reforçada pela ii) interpretação imediatista do parágrafo III do artigo 6ํㅜ da lei de criação dos institutos, cuja apropriação tosca pelos gestores da instituição soube apenas destacar a necessidade de se "otimizar a infraestrutura física, os quadros de pessoal e os recursos de gestão" disponíveis naquele momento, ignorando a clara vinculação e subordinação dessa otimização à futura "integração e verticalização da educação básica à educação profissional e educação superior" dos eixos de oferta dos novos campi, de acordo com as necessidades das suas específicas novas regiões de atuação; iii) além disso, não foram criadas internamente normas para regulamentação do processo de expansão do IFMG, em conformidade com os princípios legalmente estabelecidos, o que acabou submetendo a sistematicidade e a qualidade político-pedagógica dessas decisões fundamentais aos voluntarismos dos gestores de primeira hora. ${ }^{6}$

Portanto, vê-se que a recusa a atender o arrojado projeto políticoeducacional dos Institutos Federais de Educação, Ciência e Tecnologia nesse tópico fundamental da composição da sua oferta de vagas não é resultado de uma decisão institucional consciente, oficializada; tampouco justifica-se quantitativamente como correção de uma insustentável ineficiência da oferta legalmente determinada. Impondo-se a conclusão de que o não atendimento à oferta de vagas e, consequentemente, ao perfil institucional pretendido quando da criação da RFEPCT brasileira deve-se a uma irrefletida, inercial, posição político-pedagógica; que, sendo inercial, não poderia expressar-se senão pela resistência ao desenvolvimento de toda forma de oferta que já não fosse adotada ou estivesse mais diretamente relacionada às áreas presentes nos campi mais antigos.

Por isto, o deficit na oferta dos cursos de Licenciatura. Por isto, a completa ausência justamente da mais disfuncional forma de oferta determinada pela legislação, se se considera a composição da oferta preexistente, o PROEJA: ensino médio integrado à educação profissional, não para adolescentes, mas para jovens e adultos; jovens e adultos não exclusivamente estudantes, como ocorre na oferta regular do ensino superior, mas já atuantes no mercado de trabalho. Oferta crucial, capaz de sintetizar, como nenhuma outra forma de oferta, o desafio histórico legado aos Institutos Federais de Educação Profissional, Científica e Tecnológica - pela intensidade com que perturbaria a tendência inercial das comunidades acadêmicas, forçando radicais transformações curriculares, didáticas, relacionais e infraestruturais, justamente naquele seu sentido fundante de relativização das tradicionais hierarquias do processo de ensino-

5 O estudo detalhado desses fatores, aqui brevemente referidos, será publicado em artigo posterior.

6 No IFMG, apenas em 2017 foi aprovada por seu Conselho Superior uma resolução para normatização do processo de criação de novos cursos: Resolução IFMG/CONSUP no 45/2017. Disponível em: https://www2.ifmg.edu.br/portal/acesso-a-informacao/conselhosuperior/resolucoes/2017/resolucao-045-2017-regulamento-criacao-de-cursos/view 
aprendizagem e cada vez maior imbricação com o mundo do trabalho. Recusa prática que, somada à minguada presença das Licenciaturas, tem colocado em sério risco a capacidade de rompimento da inércia e enfrentamento qualificado aos principais desafios didático-pedagógicos especificados na institucionalidade da Rede Federal de Educação Profissional, Científica e Tecnológica.

\section{DA TIPICIDADE DO CASO DO IFMG E DAS POSSIBILIDADES DE CORREÇÃO DA OFERTA DE VAGAS PARA EFETIVAÇÃO DO POTENCIAL POLÍTICO-EDUCACIONAL DOS INSTITUTOS FEDERAIS DE EDUCAÇÃO PROFISSIONAL, CIENTÍFICA E TECNOLÓGICA}

Apesar de suas motivações objetivamente injustificáveis, não oficializáveis, e reforçando a tese acima apresentada, o caso do IFMG parece mesmo representar um caso típico, quando se considera a composição da oferta de vagas de toda a RFEPCT, em 2018 - igualmente deficitária na oferta de vagas em cursos de Licenciatura e PROEJA.

Tabela 6: composição da oferta de vagas de toda a RFEPCT.

\begin{tabular}{l|l|l|l|} 
& Nível/Modalidade de curso & Porcentagem das vagas totais \\
\hline & Cursos técnicos & $64,7 \%$ & \\
\hline Cursos de formação de professores & $9,5 \%$ & \\
\hline & Proeja & $2,4 \%$ & \\
\hline Bacharelados e pós-graduação & $23,4 \%$ & \\
\hline $\begin{array}{l}\text { Fonte: } \\
\text { www.plataformanilopecanha.org Peçanha: ano-base 2018. Disponível em: }\end{array}$ & & & \\
plataforma Nilo em
\end{tabular}

Restando-nos, então, investigar se ainda há capacidade de correção dessa inadequação para atendimento à oferta de vagas determinada pela legislação; acreditando que tal correção representaria, pelos motivos até aqui elencados, o primeiro passo necessário para efetivação qualificada do arrojado projeto fundante da RFEPCT, evitando a sua acomodação histórica pela mera reprodução inercial da tradição que lhe cumpria superar.

Para isto, retomemos nosso caso típico, cujo potencial de expansão e correção de rumos será possível dimensionar aproximadamente, multiplicando-se: a quantidade de vagas ainda previstas para contratação de docentes, até a consolidação de cada um dos campi do IFMG, conforme Portaria MEC no 246, de 15 de Abril de 2016, por uma carga horária média de trabalho docente de 13,3 horais semanais, exercida durante 40 semanas anuais. $^{7}$

Tabela 6: margem disponível para expansão e possível correção da oferta, conforme Modelo MEC.

7 A opção por tal carga-horária média de trabalho em sala de aula, levou em conta a divisão da carga-horária total, de 40 horas de trabalho, entre as três dimensões básicas do trabalho docente: ensino, pesquisa e extensão. 


\begin{tabular}{|l|l|l|l|}
\hline & & $\begin{array}{l}\text { contratação, conforme } \\
\text { modelo MEC }\end{array}$ & cursos \\
\hline Arcos & 9 & 11 & 5852 \\
\hline Bambuí & 135,5 & 14,5 & 7714 \\
\hline Betim & 56 & 14 & 7448 \\
\hline Congonhas & 65,5 & 4,5 & 2394 \\
\hline Conselheiro Lafaiete & 19 & 1 & 532 \\
\hline Formiga & 67 & 3 & 1596 \\
\hline Governador Valadares & 49 & 21 & 11172 \\
\hline Ipatinga & 19 & 1 & 532 \\
\hline Itabirito & 18 & 2 & 1064 \\
\hline Ouro Branco & 63,5 & 6,5 & 3458 \\
\hline Ouro Preto & 164,5 & 0 & 0 \\
\hline Piumhi & 15 & 5 & 2660 \\
\hline Ponte Nova & 20 & 0 & 0 \\
\hline Ribeirão das Neves & 27 & 43 & 22876 \\
\hline Sabará & 35 & 35 & 18620 \\
\hline Santa Luzia & 47 & 23 & 12236 \\
\hline São João Evangelista & 83 & 7 & 3724 \\
\hline IFMG & 893 & 191,5 & 101878 \\
\hline Fonte: Sistema de Ges & 0 Acand & \\
\hline
\end{tabular}

Fonte: Sistema de Gestão Acadêmica do IFMG adaptado em 20/01/2018.

Pelo método proposto, calcula-se, então, um potencial total aproximado de expansão da oferta pela contratação de novos docentes, de 101.878 horas. Se quisermos dimensionar o esforço necessário para sua correção, considerando, por exemplo, a criação de cursos de Licenciatura e cursos PROEJA com a carga horária mínima exigida de, respectivamente, 3.200 e 2.400 horas, ofertando em todos os casos, 40 vagas por turma; seria necessária a criação de, no mínimo, 22 novas turmas em cursos de Licenciatura, quadruplicando-se a oferta atual, e 12 novas turmas em cursos PROEJA. O que exigiria a destinação de 99.200 horas-aula, elevando de 4797 para 6614 a quantidade de vagas ofertadas anualmente. Ou seja, para adequação, a partir de agora, ao mínimo estabelecido pela legislação, o IFMG deveria mobilizar $98 \%$ do potencial ainda disponível na instituição para expansão da oferta de vagas pela contratação de novos docentes.

\section{CONSIDERAÇÕES FINAIS}

Em sua primeira década, o desenvolvimento do projeto educacional instituído pela Lei 11892/2018 deu-se às custas do esvaziamento da sua qualidade específica, em razão do retraimento injustificado, inercial, da oferta de cursos justamente naquelas modalidades de ensino (PROEJA e Licenciaturas), em torno das quais, por sua disfuncionalidade e reflexividade, mais intensamente poderiam fazer amadurecer nas comunidades acadêmicas componentes da Rede Federal de Educação Profissional, Científica e 
Tecnológica, sua pretendida especificidade político-educacional. Compreendemos que o relativo abandono das diretrizes propostas na lei aconteceu em decorrência da sobreposição das experiências historicamente consolidadas nas instituições antecessoras às determinações legais que fundaram o projeto dos institutos federais, e da falta de normatização interna que qualificasse e conferisse sistematicidade ao processo de expansão de seus campi, ocorrido nos últimos dez anos. Demonstramos, por fim, que a correção, ao menos quantitativa, dos rumos da RFEPCT à luz do seu projeto fundante, exigiria o direcionamento de quase todo o seu potencial de expansão ainda disponível para a oferta de vagas em cursos de formação de professores e na educação profissional de jovens e adultos.

\section{REFERÊNCIAS}

BRASIL. Lei no 11.892, de 29 de Dezembro de 2008. . Decreto $n^{\circ}$ 5840, de 13 de Julho de 2016.

Ministério da Educação. Secretaria de Educação Profissional e Tecnológica. Instituto Federal de Minas Gerais. Edital ํㅡ 62, de 30 de Maio de 2017.

- Ministério da Educação. Secretaria de Educação Profissional e Tecnológica. Instituto Federal de Minas Gerais. Edital no 92, de 20 de Setembro de 2017.

Ministério da Educação. Secretaria de Educação Profissional e Tecnológica. Portaria ํㅡㄹ 25, de 13 de Agosto de 2015.

Ministério da Educação. Secretaria de Educação Profissional e Tecnológica. Educação Profissional Técnica de Nível Médio Integrada ao Ensino Médio: Documento Base. Brasília, 2007.

Ministério da Educação. Secretaria de Educação Profissional e Tecnológica. Catálogo Nacional de Cursos Técnicos - $3^{a}$ edição. Brasília, 2016. Disponível

em: http://portal.mec.gov.br/index.php?option=com_docman\&view=download\&alia $\mathrm{s}=77451$-cnct-3a-edicao-pdf-1\&category_slug=novembro-2017pdf\&ltemid $=30192$

Ministério da Educação. Portaria no 246, de 15 de Abril de 2016. Ministério da Educação. Portaria № 870, de 16 de Julho de 2008.

CAIRES, Vanessa, OLIVEIRA, Maria Auxiliadora Monteiro. Educação profissional Brasileira: da colônia ao PNE 2014-2024. Petrópolis: Vozes, 2016.

CARDOSO, Sheila Pressentin. Aspectos da Gestão em um Instituto Federal. In: ANJOS, Maylta Brandão dos; RÔÇAS, Giselle (orgs.). As Políticas Públicas e o Papel Social dos Institutos Federais de Educação Profissional, Científica e Tecnologia. Natal: Editora IFRN, 2017, p. 36-59. INSTITUTO FEDERAL DE MINAS GERAIS. A Evasão Escolar no IFMG: diagnóstico e diretrizes da política institucional para a permanência e o êxito dos estudantes. Belo Horizonte, 2016. Disponível em: https://www.ifmg.edu.br/portal/links/relatorio-evasao-completo-rev6.pdf PLATAFORMA NILO PEÇANHA. Resultados ano base 2017. Disponível em: http://resultados.plataformanilopecanha.org/2018/ 
SILVA, Caetana Juracy Resende (Org.). Institutos Federais, Lei 11.892, de 29/12/2008: comentários e reflexões. Natal: Editora IFRN, 2009. 